\title{
НЕЙРО-НЕЧЕТКОЕ МОДЕЛИРОВАНИЕ ПРОЦЕССОВ РАБОТЫ ИНДУКТИВНО-ПРОВОДНОГО ДАТЧИКА
}

\author{
Представил д-р техн. наук, профессор М.М. Бабаев
}

Введение. В условиях стремительного роста скоростей движения поездов и увеличения объема грузовых перевозок назрела необходимость в улучшении существующих технологий, повышении эффективности использования пропускных и перерабатывающих способностей станций, а также внедрении инновационных технических средств. В настоящее время для усиления контроля состояния путевых участков железнодорожных объектов перспективны разработка и модернизация путевых датчиков, в частности индуктивнопроводных датчиков (ИПД), которые являются важными составляющими систем автоведения поездов, контроля заполнения путей, горочной автоматической централизации и др. [1]. Однако совершенствование систем железнодорожной автоматики и телемеханики требует новых подходов к разработке, представлению и испытанию технических средств. Для удовлетворения данных требований необходимым становится применение такой технологии, которая позволит обеспечить сравнительно дешевую и гибкую среду для поиска и проверки исследовательских решений, a также значительно ускорить процессы обработки информации.

На сегодняшний день одним из самых мощных инструментов, обладающих широкими вычислительными возможностями и огромным потенциалом, являются искусственные нейронные сети (HC). НC - это исключительно мощный метод моделирования, который позволяет наглядно воспроизводить сложнейшие зависимости. НС открывают возможности использования вычислений в сферах, до этого относящихся только к области человеческого интеллекта, возможности создания систем, способных обучаться, запоминать и обрабатывать данные [2].

Анализ публикаций и постановка задачи исследования. Использование методов моделирования для решения проблем транспортной сети рассмотрено в работе [3]. На сети железных дорог нейросетевое моделирование наращивает свои позиции в области управления 
процессами перевозок: в работе [4] занимаются прогнозированием объемов нагрузки в вагонах, подходы к реализации управленческих решений рассматривают в материалах [5, 6]. Применительно к железнодорожной автоматике в статье [7] с помощью НC проведена оптимизация структур современных компьютерных систем управления движением поездов. Вместе с этим можно утверждать, что необходимость решения насущных именно для железной дороги задач с помощью имитационного моделирования способствует повышению уровня безопасности движения и эксплуатации объектов железнодорожного транспорта и улучшает качество перевозочного процесса в целом. С другой стороны, анализ состояния технических средств контроля подвижных объектов [8] позволяет сделать вывод о необходимости усовершенствования существующих путевых датчиков, и конкретно ИПД как ключевого звена в регулировании движения поездов. Поэтому осуществить улучшение качественных характеристик датчика возможно путем моделирования процессов его работы. Т. к. основной функцией ИПД является выявление наличия транспортного средства на путевом участке, то задачей, на выполнение которой направлено данное исследование, является реализация процесса определения занятости/свободности контрольного участка пути подвижной единицей с помощью НС.

Основная часть. На основе разработанного усовершенствованного ИПД [9] была создана соответствующая имитационная модель в пакете Simulink среды Matlab [1]. Анализ сведений, полученных при испытании данной модели, показал, что исходные данные изменения индуктивности секций шлейфа слабо формализованы. В различных условиях индуктивность каждой из секций может принимать любые значения на определенном интервале. Следовательно, при исследовании возможно рассматривать изменение индуктивности как нечеткое множество. В данном случае, когда анализируемые колебания индуктивности под влиянием дестабилизирующих факторов имеют различные значения, целесообразным будет применение нейронечеткого моделирования. Система нечеткого вывода позволяет построить модель, адекватную действительности, с помощью математической формализации нечетких данных [10]. Исходя из этого представляется возможным построение модели реализации процессов работы ИПД в виде системы на базе нечетких правил Fuzzy Inference System (FIS).

B качестве программы для математического моделирования используется пакет Matlab, потому как он является одновременно интегральной средой разработки систем нечеткого вывода и нейронных сетей.

Разрабатываемая модель будет содержать два входа. Учитывая, что индуктивный шлейф, который является чувствительным элементом ИПД, содержит две секции, уложенные последовательно внутри рельсовой колеи, представим входные параметры модели в виде нечетких переменных, каждая из которых соответствует процентному изменению индуктивности секций при различных состояниях пути. Руководствуясь результатами исследования изменения индуктивности катушки при свободности пути и при наличии над катушкой ферромагнитной массы подвижной единицы [11], а также результатами моделирования [1], будем считать, что изменение индуктивности в пределах от 0 до $15 \%$ вызвано климатическими и другими внешними воздействиями. Наличие подвижного состава на контрольном участке пути определяется изменением индуктивности от 16 до $100 \%$.

Как систему нечеткого логического вывода используем адаптивную модель с настройками с помощью HC FIS типа Sugeno, применяющую «обучение с 
учителем», причем в качестве образцов входных и выходных данных используем данные моделирования [1]. Алгоритм Sugeno выбран в связи с простотой реализации и большей точностью по сравнению с другими алгоритмами. Зададим Гауссовские функции как функции принадлежности для обеспечения плавных переходов между термами входной переменной, которая будет определяться на интервале $[0,1]$, что означает изменение индуктивности (0-100 \%) в долях. Ординаты максимумов этих функций совпадают с рассматриваемыми возможными значениями изменения индуктивности для первой (рис. 1, a) и для второй (рис. 1, б) секций индуктивного шлейфа. Например, возможное изменение индуктивности обеих секций вследствие дождя равно 0,1, а по причине наезда подвижного состава на первую секцию значение изменения достигает 0,9.

a)

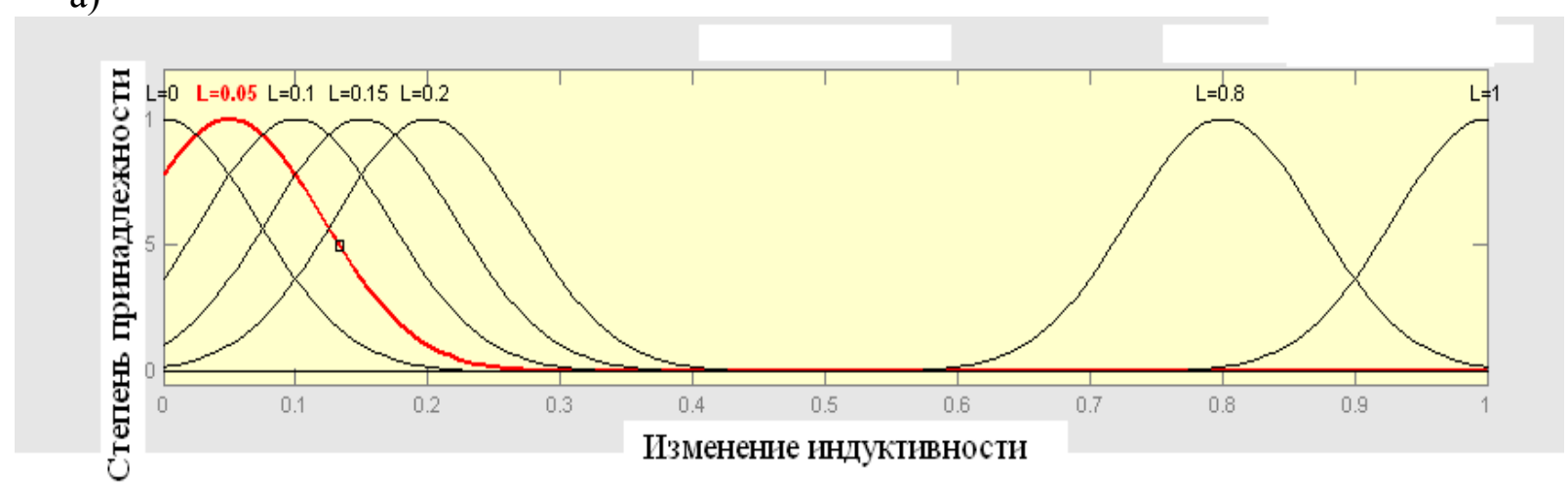

б)

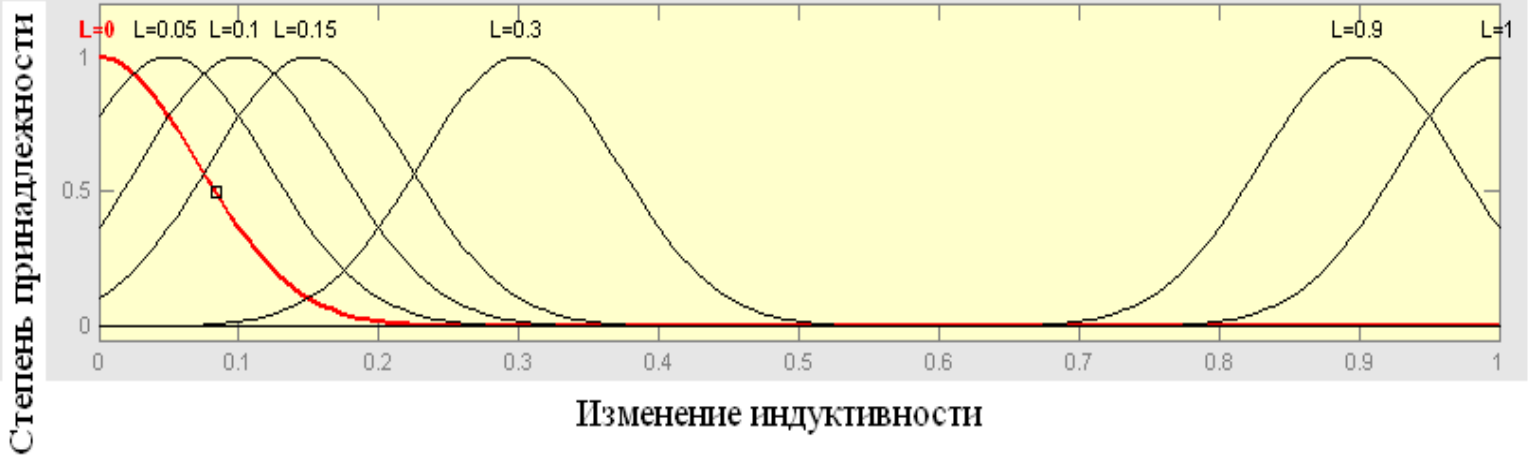

Рис. 1. Функции принадлежности входных переменных для первой секции (a) и для второй секции (б) индуктивного шлейфа

Выход модели будет представлять собой прогнозируемое состояние путевого участка в различных условиях. Для этого зададим постоянные функции принадлежности выходной переменной на интервале $[0,1]$, которые будут обозначать: «0»- участок свободен (влияние погодных и других внешних факторов), «1»- наезд подвижной единицы на контрольный участок. Главной составляющей модели нечеткого логического вывода является система правил. Введем обучающие правила, характеризующие процессы работы ИПД, обозначив соответствия между каждой функцией принадлежности и выходной переменной. Набор правил сгенерированной системы нечеткого вывода приведен на рис. 2. 


\section{Телекомунікаційні системи та управління ними}

a)
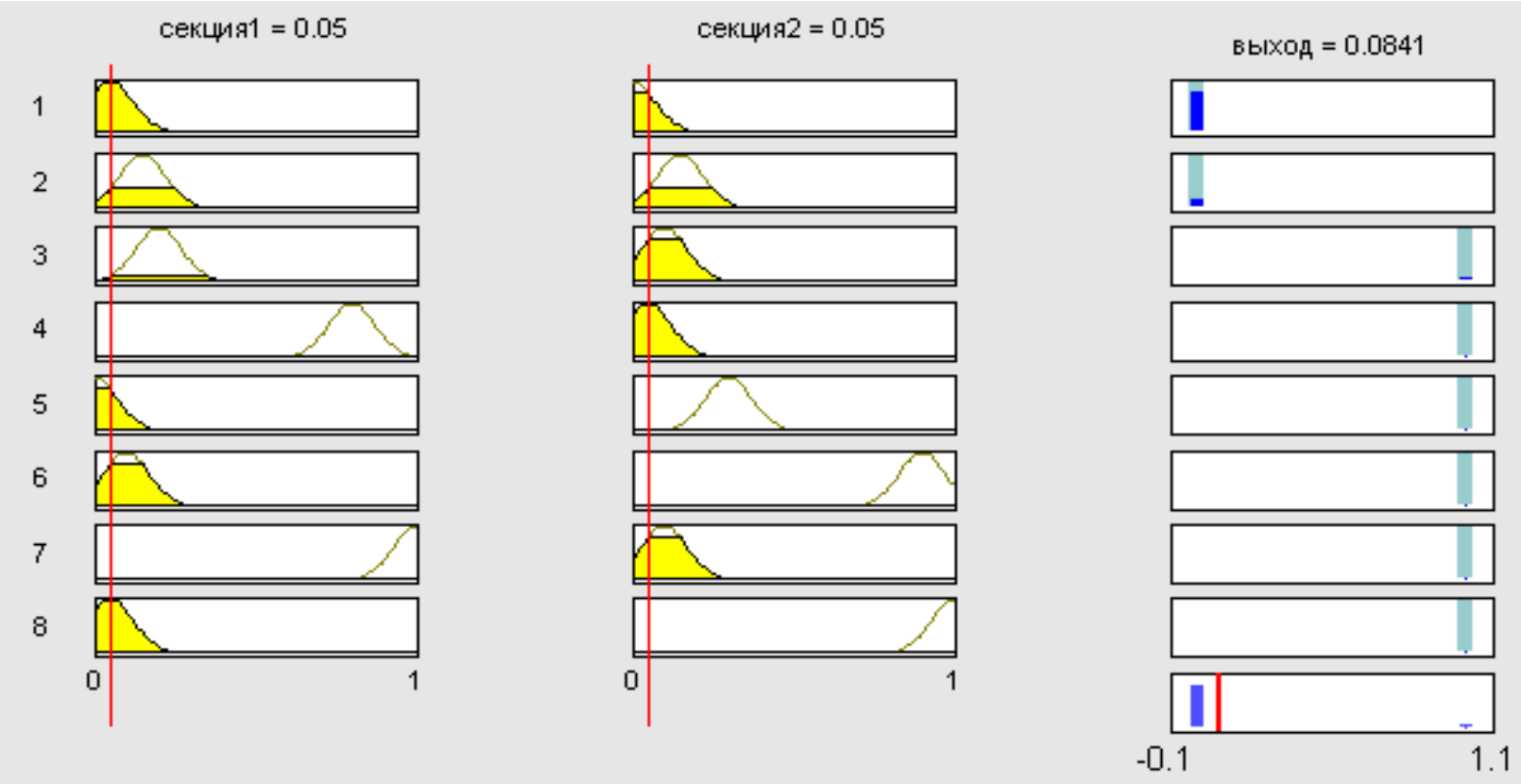

б)
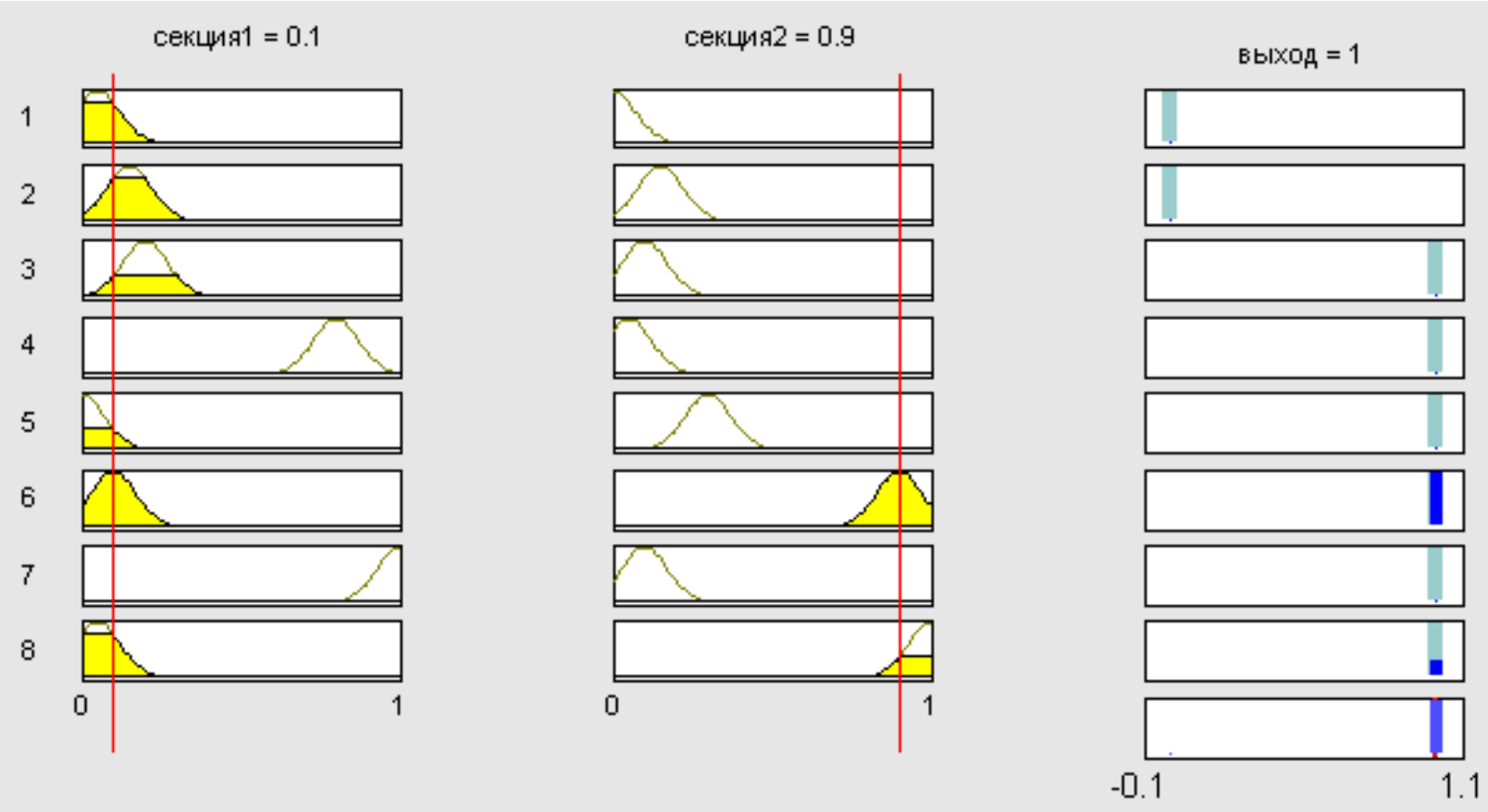

Рис. 2. Набор правил созданной системы нечеткого вывода при изменениях погодных условий (а) и при занятости путевого участка (б)

На рис. 2 первые два столбца представляют собой входы системы, соответствующие первой и второй секциям индуктивного шлейфа, индуктивность которых изменяется при различных состояниях пути. В зависимости от количества правил столбцы разбиваются на ячейки, и если в данное правило входит какая-либо функция принадлежности, то она представляется в окне нелинейной 
функцией. Третий столбец отображает значения переменной на выходе системы. Перемещая красную вертикальную линию, изменяем значение аргументов на входе, при этом, соответственно, изменяется значение переменной на выходе. На рис. 2, а показан случай скачков давления, причем изменение индуктивности обеих секций составляет не больше $5 \%$, а значение на выходе достигает «0,0841», что близко к нулю и означает свободность контрольного участка пути. В случае наезда поезда со стороны второй секции во время снегопада изменение индуктивности первой секции достигает $10 \%$, второй - $60 \%$, а значение на выходе системы составляет «1», что характерно для занятости путевого участка (рис. 2, б). Изменение аргумента с помощью красной черты наглядно демонстрирует определение системой значения выхода.

$\mathrm{HC}$, отражающая приведенный механизм вывода, состоит из четырех слоев нейронов (рис. 3). На выходах узлов первого слоя представлены аргументы функций принадлежности при конкретных значениях входных величин $a_{1}, a_{2}$. С помощью нейронов этого слоя осуществляется процедура фазификации (приведение к нечеткости) входных данных модели. Выходами нейронов второго слоя являются истинные значения для правил, составляющих базу знаний, которая была создана вследствие обучения модели. Степени истинности предпосылок каждого правила вычисляются по формулам [2]:

$$
\begin{aligned}
& b_{1}=L_{1} a_{1} \Lambda L_{8} a_{2}, \\
& b_{2}=L_{2} a_{1} \Lambda L_{9} a_{2}
\end{aligned}
$$

где $\boldsymbol{L}_{1}, \boldsymbol{L}_{2}-$ нейроны первого слоя.

Нейроны данного слоя, обозначенные буквой $T$, могут реализовывать любые варианты $T$-нормы для моделирования логической операции «И». Нейроны третьего слоя содержат конечные результаты вычислений с учетом веса каждого правила. Единственный нейрон пятого слоя рассчитывает конечный выход модели $c$, выполняя операцию дефазификации.

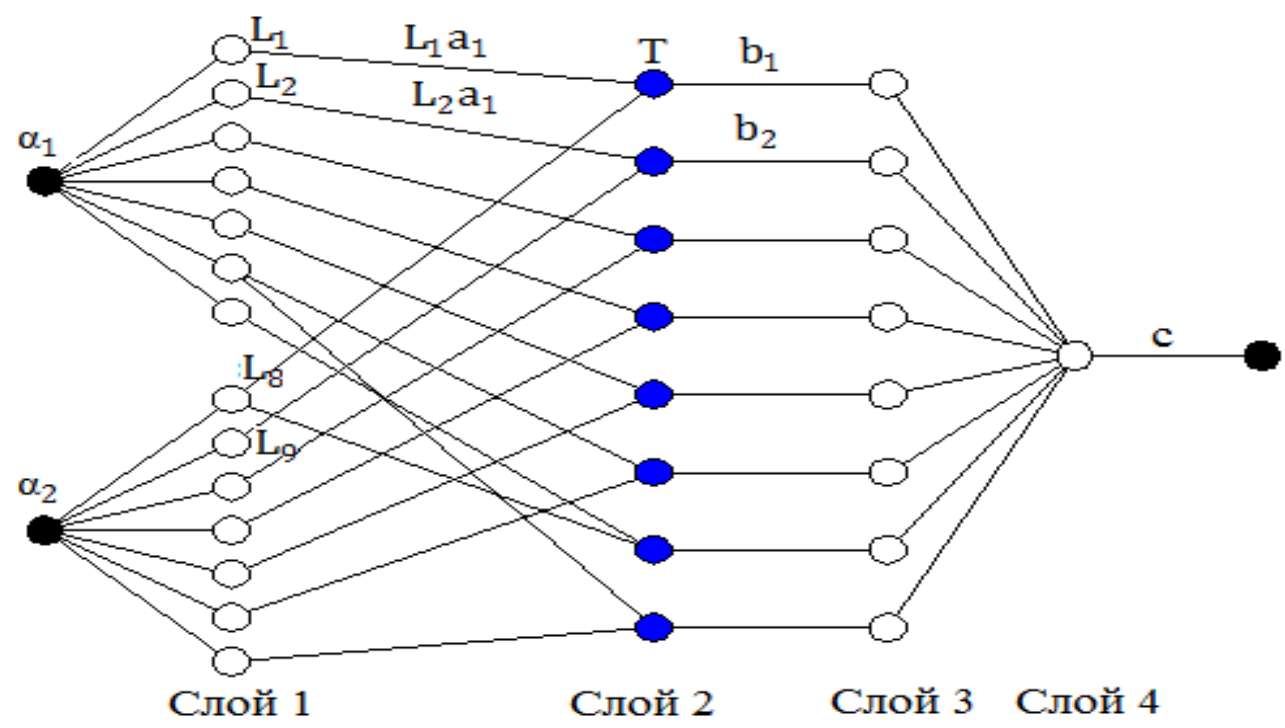

Рис. 3. Архитектура сгенерированной модели реализации процессов работы ИПД в различных условиях 
Подтверждением результатов выходной входных служит изображенная на рис. 4, показывающая зависимость изменения индуктивностей первой и второй секций индуктивного шлейфа от выходного значения, характеризующего состояние путевого участка под воздействием дестабилизирующих факторов.

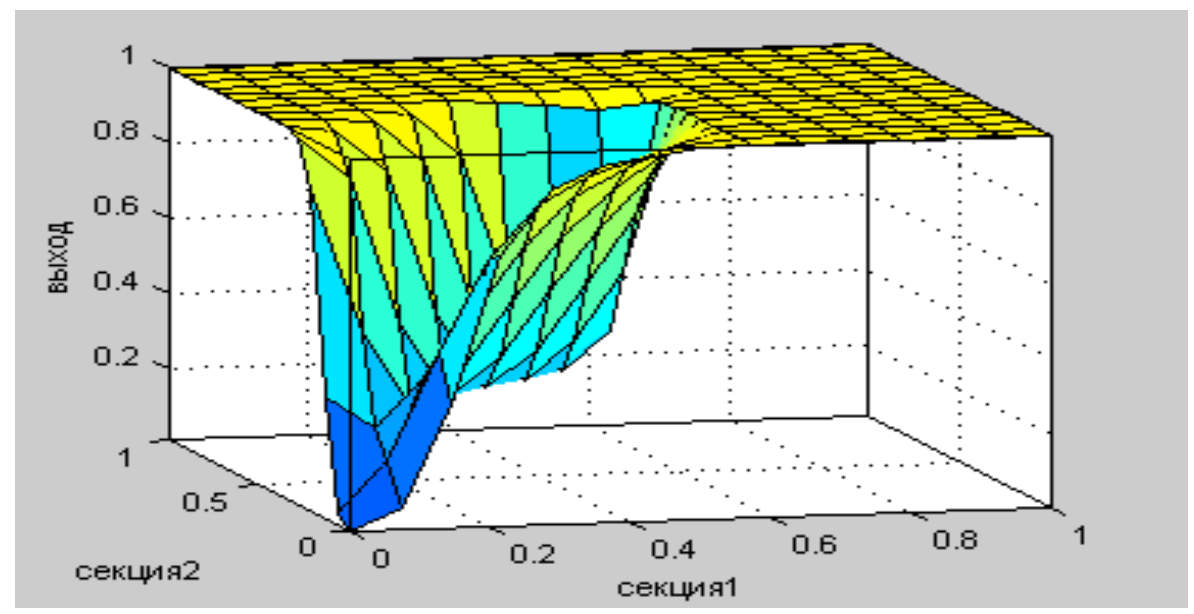

Рис. 4. Графический вид зависимости состояния путевого участка от изменения индуктивности секций шлейфа

Выводы исследования и перспективы, дальнейшее развитие в данном направлении. Таким образом, с помощью разработанной нейро-нечеткой модели ИПД решается задача выявления наличия или отсутствия транспортного средства на путевых участках железнодорожных объектов, что имеет большое значение в процессе регулирования движением поездов. С помощью системы нечеткого вывода подтверждены результаты исследований [11].

В связи с изложенным, перспективным является дальнейшее усовершенствование ИПД с помощью НС с целью улучшения его характеристик.

\section{Список литературы}

1. Гребенюк, В.Ю. Моделирование процессов работы индуктивно-проводного датчика [Текст] / В.Ю. Гребенюк // Зб. наук. праць. - Харків: УкрДАЗТ, 2012. - Вип. 134. - С. 162173.

2. Хайкин, С. Нейронные сети. Полный курс [Текст] / пер. с англ. - 2-е изд. - М.: Издательский дом «Вильямс», 2006. - 1104 с.

3. Ахмадинуров, М.М. Обзор методов моделирования транспортной сети [Текст] / М.М. Ахмадинуров // Транспорт Урала. - 2009. - № 3 (22). - С. 39-44.

4. Мкртичьян, Д.І. Розроблення математичної моделі прогнозування обсягів навантаження 3 використанням нейро-нечіткого моделювання [Текст] / Д.І. Мкртичьян, О.В. Розсоха, О.М. Костєнніков, С.А. Ільченко // Зб. наук. праць. - Харків: УкрДАЗТ, 2012. Вип. 133. - С. 45-51.

5. Рибальченко, Л.І. Підходи до реалізації системи підтримки прийняття рішення оперативного управління за допомогою сучасних технологій моделювання [Текст] / 
Л.І. Рибальченко // Інформаційно-керуючі системи на залізничному транспорті. - 2012. - № 5. - C. 20-24.

6. Костєнніков, О.М. Формалізація технології організації місцевої роботи на полігоні дирекції залізничних перевезень [Текст] / О.М. Костєнніков // Зб. наук. праць. - Харків: УкрДАЗТ, 2012. - Вип. 134. - С. 27-33.

7. Кузьменко, Д.М. Нейромережне моделювання функцій систем залізничної автоматики [Текст] / Д.М. Кузьменко, В.С. Блиндюк, М.М. Чепцов // Зб. наук. праць. Харків: УкрДАЗТ, 2011. - Вип. 122. - С. 33-43.

8. Гребенюк, В.Ю. Анализ современных путевых датчиков контроля подвижных объектов железнодорожного транспорта [Текст] / В.Ю. Гребенюк // Інформаційно-керуючі системи на залізничному транспорті. - 2012. - № 3. - С. 70-75.

9. Індуктивно-дротовий датчик для виявлення транспортного засобу в межах певної ділянки шляху [Текст]: пат. 69618 України: МПК В 61 L 1/00, / Бабаєв М.М., Блиндюк В.С., Ананьєва О.М., Гребенюк В.Ю.; власник Українська державна академія залізничного транспорту. - № u 201111537; заявл. 29.09.2011; опубл. 10.05.2012, Бюл. № 9. - 4 с.

10. Рутковская, Д. Нейронные сети, генетические алгоритмы и нечеткие системы [Текст] / пер. с польского И.Д. Рудинского. - М.: Горячая линия - Телеком, 2006. - 452 с.

11. Бабаєв, М.М. Аналіз впливу феромагнітної маси рухомої одиниці на індуктивні датчики систем залізничної автоматики [Текст] / М.М. Бабаєв, М.Г. Давиденко, В.Ю. Гребенюк // Зб. наук. праць. - Харків: УкрДАЗТ, 2012. - Вип. 129. - С. 117-123.

Ключевые слова: индуктивно-проводной датчик, индуктивный шлейф, нейронная сеть, нейро-нечеткое моделирование, система нечеткого логического вывода, фазификация.

\section{Аннотации}

Описана в статті імітаційна модель процесів роботи індуктивно-дротового датчика (ІДД) дозволяє відтворити реальну картину колійної ділянки, задати можливу зміну індуктивності секцій індуктивного шлейфу, а також врахувати кліматичні та інші зовнішні чинники, після чого контролювати стан даної ділянки в заданих умовах. За допомогою нейро-нечіткого моделювання вирішено завдання реалізації процесів роботи ІДД в різних умовах.

Описанная в статье имитационная модель процессов работы индуктивно-проводного датчика (ИПД) позволяет воссоздать реальную картину путевого участка, задать возможное изменение индуктивности секций индуктивного шлейфа, а также учесть климатические и другие внешние факторы, после чего контролировать состояние данного участка в заданных условиях. С помощью нейро-нечеткого моделирования решена задача реализации процессов работы ИПД в различных условиях.

The described simulation model of the processes of the inductive-wire sensor (IWS) to recreate the real picture of track section, set a possible change in the inductance of the inductive loop sections, as well as to take into account the climatic and other external factors, and then to monitor the state of the control area in the given conditions. Using neuro-fuzzy modeling solved the problem of IWS implementation processes under different conditions. 